\title{
Comment on an article: "Medications in COVID-19 patients: summarizing the current literature from an orthopaedic perspective"
}

\author{
Omer Ć. Ibrahimagić ${ }^{1} \cdot$ Zlatko Ercegović $^{2} \cdot$ Aleksandar Vujadinović $^{3} \cdot$ Suljo Kunić $^{4}$ (D)
}

Received: 4 August 2020 / Accepted: 21 August 2020 / Published online: 24 August 2020

(C) SICOT aisbl 2020

Dear Editor-in-Chief Marius M. Scarlat,

We have read with great attention the article "Medications in COVID-19 patients: summarizing the current literature from an orthopaedic perspective", written by Shi Heng Sharon Tan and colleagues (Authors) in the forthcoming August issue of International Orthopaedics [1]. We welcome the opportunity to make a short comment as well.

This very interesting article evaluates current literature regarding common medications prescribed in orthopaedic surgery and their potential implications in COVID-19 patients. The Authors emphasized that vitamins are commonly prescribed in various orthopaedic conditions. We want to highlight that older people are in increased risk for mortality due to pandemic of COVID-19, but also for different vascular accidents after hip and/or other bone fractures. Also, hyperhomocysteinemia is common in elderly people and often associated increased risk for fractures and cardiovascular diseases, too. Interestingly, values of vitamin B9 (folic acid) and B12 are in negative correlation with levels of homocysteine [2]. Unfortunately, hyperhomocysteinemia appeared to be predictive of all-cause mortality, independent of frailty, an agerelated clinical state characterized by a global impairment of physiological functions and involving multiple organ systems [3].

Suljo Kunić

suljo.kunic@hotmail.com

1 Department of Neurology, University Cinical Centre Tuzla, 75000 Tuzla, Bosnia and Herzegovina

2 Department of Neurosurgery, University Cinical Centre Tuzla, 75000 Tuzla, Bosnia and Herzegovina

3 Department of Orthopaedics and Traumatology, University Cinical Centre Tuzla, 75000 Tuzla, Bosnia and Herzegovina

4 Present address: Department of Neurology, Primary Health Care Centre Tuzla, Albina i Franje Herljevića 1, 75000 Tuzla, Bosnia and Herzegovina
In one of the very rare studies, high number of pulmonary embolism was noted in COVID-19 pneumonia patients (20.6\%), despite the fact that $90 \%$ of them were receiving prophylactic antithrombotic treatment due to the current guidelines [4]. Furthermore, according to PubMed survey, there was no reliable data due to concomitance of COVID19 , hyperhomocysteinemia and osteoporosis/fractures. So, what to do when we have older COVID-19 patient with high risks for different cardiovascular diseases, including pulmonary thromboembolism, as well as bone fracture?

There is an urgent need to different opinions and recommendations, when proper data are absent due to enormous speed of COVID-19 disaster. Clinicians need to adapt to the challenges posed by this crisis and consider ways to continue serving the most vulnerable amongst us, those with chronic disease with their own substantive morbidity and mortality [5].

In light of this, we suggest that level of homocysteine and B9/B12 vitamin should be measured at clinical follow-up in all patients with COVID-19, immediately after hospitalization. If persistent, hyperhomocysteinemic proosteoporotic/ procoagulability state should be promptly decreased in acute phase of COVID-19, on the base of Latin phrase primum non nocere.

Our studies from Bosnia and Herzegovina showed that the intake of B9 vitamin, sometimes with B12 vitamin as well, was efficient in creating normalized homocysteine levels in older patients with ischemic stroke and Parkinson's disease [6, 7]. Fortunately, risk of side effects is minimal if the daily dose of B9 vitamin is $1-5 \mathrm{mg}$ [8]. In addition, B2/B3/B6 vitamins are, as Authors wrote, enhancers of the immune system and might be efficient as soldiers from second echelon in battling with COVID-19. Lastly, we emphasize that further studies will elucidate hidden but also harmful potential of hyperhomocysteinemia on bone fractures/vascular accidents in COVID-19 patients as well as beneficial add-on effects of B9/B12 vitamin on their osteoporotic/vascular complications. 


\section{References}

1. Tan SHS, Hong CC, Saha S, Murphy D, Hui JH (2020) Medications in COVID-19 patients: summarizing the current literature from an orthopaedic perspective. Int Orthop 44(8):1599-1603. https://doi. org/10.1007/s00264-020-04643-5

2. B-Vitamin Treatment Trialists' Collaboration (2006) Homocysteinelowering trials for prevention of cardiovascular events: a review of the design and power of the large randomized trials. Am Heart $\mathbf{J}$ 151(2):282-287. https://doi.org/10.1016/j.ahj.2005.04.025

3. Azzini E, Ruggeri S, Polito A (2020) Homocysteine: its possible emerging role in at-risk population groups. Int J Mol Sci 21(4): 1421. https://doi.org/10.3390/ijms21041421

4. Poissy J, Goutay J, Caplan M et al (2020) Pulmonary embolism in COVID-19 patients: awareness of an increased prevalence. Circulation 142(2):184-186. https://doi.org/10.1161/circulationaha. 120.047430
5. Girgis CM, Clifton-Bligh RJ (2020) Osteoporosis in the age of COVID-19. Osteoporos Int:1-3. https://doi.org/10.1007/s00198020-05413-0

6. Ibrahimagić OĆ, Smajlović D, Dostović Z, Pašić Z, Šehanović A, Hodžić R (2012) Hyperhomocysteinemia and its treatment in patients with ischemic stroke. Medicus 21(2):267-272

7. Ibrahimagić OĆ, Smajlović D, Dostović Z et al (2016) Hyperhomocysteinemia and its treatment in patients with Parkinson's disease. Mater Soc 28(4):303-306. https://doi.org/10. 5455/msm.2016.28.303-306

8. Belcastro V, Pierguidi L, Castrioto A et al (2010) Hyperhomocysteinemia recurrence in levodopa-treated Parkinson's disease patients. Eur J Neurol 17(5):661-615. https://doi.org/10. 1111/j.1468-1331.2009.02984.x

Publisher's note Springer Nature remains neutral with regard to jurisdictional claims in published maps and institutional affiliations. 